\title{
Preparation and Luminescence characteristics of $\mathrm{Na}_{2} \mathrm{O}-\mathrm{PbO}-\mathrm{SiO}_{2}$ system long afterglow Luminescent glasses
}

\author{
Wen $\mathrm{Yi}^{1, \mathrm{a}}$ \\ ${ }^{1}$ Wuhan Donghu University, Wuhan 430212, China \\ a1277122054@qq.com
}

Keywords: Long afterglow; Luminescent glass; $\mathrm{SrAl}_{2} \mathrm{O}_{4}$ : $\mathrm{Eu}^{2+}, \mathrm{Dy}^{3+}$ phosphors; Preparation; Luminescence characteristics

\begin{abstract}
In this paper, the $\mathrm{Na}_{2} \mathrm{O}-\mathrm{PbO}-\mathrm{SiO}_{2}$ system long afterglow luminescent glasses of $\mathrm{SrAl}_{2} \mathrm{O}_{4}$ : $\mathrm{Eu}^{2+}, \mathrm{Dy}^{3+}$ were prepared. XRD analysis indicates the glass samples have the typical diffraction peaks of $\mathrm{SrAl}_{2} \mathrm{O}_{4}: \mathrm{Eu}^{2+}, \mathrm{Dy}^{3+}$. The emission spectra of the luminescent glass shows broad bands peaking at $510 \mathrm{~nm}$. The excitation spectra of the luminescent glass shows broad bands ranging from 300 to $480 \mathrm{~nm}$. The afterglow luminescence of the luminescent glasses which are excited by a $40 \mathrm{~W}$ fluorescence lamp for 30min can be observed in the dark for more 10 hours with the naked eyes.
\end{abstract}

\section{Introduction}

In recent years, a new type of long afterglow phosphors have been synthesized ${ }^{[1]}$, an example of these is $\mathrm{SrAl}_{2} \mathrm{O}_{4}: \mathrm{Eu}^{2+}, \mathrm{Dy}^{3+}$ [2-3]. $\mathrm{SrAl}_{2} \mathrm{O}_{4}: \mathrm{Eu}^{2+}, \mathrm{Dy}^{3+}$ is very different from previous sulfide phosphors and the brightness and afterglow time of this kind of phosphors are more than 10 times larger than the previous ones $^{[4-6]}$. Furthermore, it has excellent properties such as highway, railway, airport, ferry, texture, watch and automobile ${ }^{[7]}$.

But up to the present, the researches about long afterglow luminescence are focus on $\mathrm{SrAl}_{2} \mathrm{O}_{4}: \mathrm{Eu}^{2+}$, $\mathrm{Dy}^{3+}$ phosphors [8-10] and there are only few literatures about luminescent glasses made of $\mathrm{SrAl}_{2} \mathrm{O}_{4}$ : $\mathrm{Eu}^{2+}, \mathrm{Dy}^{3+}$ phosphors to our knowledge. In this paper, the $\mathrm{Na}_{2} \mathrm{O}-\mathrm{PbO}-\mathrm{SiO}_{2}$ system long afterglow luminescent glasses of $\mathrm{SrAl}_{2} \mathrm{O}_{4}: \mathrm{Eu}^{2+}, \mathrm{Dy}^{3+}$ phosphors have been prepared and there performances have been researched. The obtained luminescent glasses (LGs) have bright green phosphorescence for more than $10 \mathrm{~h}$ after switching off the exciting source and applications widely in many fields.

\section{Experimental}

Preparation of $\mathrm{SrAl}_{2} \mathrm{O}_{4}: \mathbf{E u}^{2+}, \mathbf{D y}^{3+}$ phosphors. The powders of $\mathrm{SrAl}_{2} \mathrm{O}_{4}$ : $\mathrm{Eu}^{2+}, \mathrm{Dy}^{3+}$ phosphors were prepared by calcining the mixture of $\mathrm{SrCO}_{3}, \mathrm{Al}_{2} \mathrm{O}_{3}, \mathrm{Eu}_{2} \mathrm{O}_{3}$ and $\mathrm{Dy}_{2} \mathrm{O}_{3}$ according to the nominal composition of $\mathrm{SrCO}_{3} \cdot 0.1 \mathrm{Eu}_{2} \mathrm{O}_{3} \cdot 0.2 \mathrm{Dy}_{2} \mathrm{O}_{3}$ in $\mathrm{mol} \%$ at $1450^{\circ} \mathrm{C}$ for $3 \mathrm{~h}$ in a reducing atmosphere of $\mathrm{H}_{2} / \mathrm{N}_{2}$ mixed gas in a $\mathrm{Al}_{2} \mathrm{O}_{3}$ crucible. They were pulverized and sieved using a 200 mesh screen.

Preparation of matrix glasses. The glass systems of $\mathrm{Na}_{2} \mathrm{O}-\mathrm{PbO}-\mathrm{SiO}_{2}$ were used to prepare matrix glasses. The mixed $100 \mathrm{~g}$ batches of $\mathrm{H}_{3} \mathrm{BO}_{3}, \mathrm{SiO}_{2}, \mathrm{PbO}, \mathrm{Na}_{2} \mathrm{CO}_{3}, \mathrm{SrCO}_{3}$ and $\mathrm{Sb}_{2} \mathrm{O}_{5}$ were melted in a $\mathrm{Pt}$ crucible at $1250-1350{ }^{\circ} \mathrm{C}$ for $30 \mathrm{~min}$ in a reducing atmosphere of $\mathrm{H}_{2} / \mathrm{N}_{2}$ mixed gas. The melted glass liquids were poured into a stainless steel container and quenched to the room temperature. The glass powers were obtained by pulverizing the quenched glass and sieving it by using a 200 mesh screen.

Preparation of luminescent glasses. The LGs were obtained by firing the mixture of matrix glasses with the proportions of $10 \mathrm{wt} \%, 20 \mathrm{wt} \%, 30 \mathrm{wt} \%, 40 \mathrm{wt} \%$ and $50 \mathrm{wt} \% \mathrm{SrAl}_{2} \mathrm{O}_{4}: \mathrm{Eu}^{2+}, \mathrm{Dy}^{3+}$ phosphors at $600-900^{\circ} \mathrm{C}$ for about $30 \mathrm{~min}$ and cooled down to the room temperature in a reducing atmosphere of $\mathrm{H} 2 / \mathrm{N} 2$ mixed gas. 
Measurement of properties.The emission and excitation spectra of the glasses were measured by a fluorescence spectrofluorometer (Fluoromax SPEX) with 450W Xe lamp as a source of the excitation light. The intensity decay curves of the LGs were measured using a luminescence brightness instrument (USA 1980A) after LGs were illuminated with a 40w fluorescence lamp for 30min. XRD patterns of the samples were measured using a X-ray diffractometer (Rigaku, D/max-RB) using radiation through a nickel filter with $40 \mathrm{kV}, 30 \mathrm{~mA}$.

\section{Results and Discussion}

Fig. 1 shows the decay curves of luminescent intensities with different measuring times for the LGs with different percentage contents of $\mathrm{SrAl}_{2} \mathrm{O}_{4}: \mathrm{Eu}^{2+}$, Dy ${ }^{3+}$ phosphors. The luminescent intensities increase with $\mathrm{SrAl}_{2} \mathrm{O}_{4}: \mathrm{Eu}^{2+}$, $\mathrm{Dy}^{3+}$ phosphors contents ranging from $10 \mathrm{wt} \%$ to $50 \mathrm{wt} \%$. The LG with more than $50 \mathrm{wt} \% \mathrm{SrAl}_{2} \mathrm{O}_{4}: \mathrm{Eu}^{2+}, \mathrm{Dy}^{3+}$ phosphors shows rough surfaces because $\mathrm{SrAl}_{2} \mathrm{O}_{4}: \mathrm{Eu}^{2+}, \mathrm{Dy}^{3+}$ phosphors cannot be encapsulated completely by the matrix glass for too much $\mathrm{SrAl}_{2} \mathrm{O}_{4}$ : $\mathrm{Eu}^{2+}, \mathrm{Dy}^{3+}$ phosphors particles during the firing stage. Therefore, the $\mathrm{SrAl}_{2} \mathrm{O}_{4}: \mathrm{Eu}^{2+}, \mathrm{Dy}^{3+}$ phosphors content in the LG should be less than $50 \mathrm{wt} \%$. Depending on the application requirements the contents of the $\mathrm{SrAl}_{2} \mathrm{O}_{4}: \mathrm{Eu}^{2+}, \mathrm{Dy}^{3+}$ phosphors can vary from $20 \mathrm{wt} \%$ to $45 \mathrm{wt} \%$. In our experiment, the optimal percentage composition of the $\mathrm{SrAl}_{2} \mathrm{O}_{4}: \mathrm{Eu}^{2+}$, $\mathrm{Dy}^{3+}$ phosphors is $30 \mathrm{wt} \%$ in the $\mathrm{Na}_{2} \mathrm{O}-\mathrm{PbO}-\mathrm{SiO}_{2}$ system long afterglow luminescent glasses. On one hand, the lifetime of afterglow meets for the equation $I(t)=I_{0} t^{-n}$, where $I(t)$ is the intensity at the time $t, I_{0}$ is the initial intensity and $n$ is a slope coefficient. On the other hand, the afterglow luminescent times of the LG can be seen in the dark for more 10 hours after switching of the excitation source light.

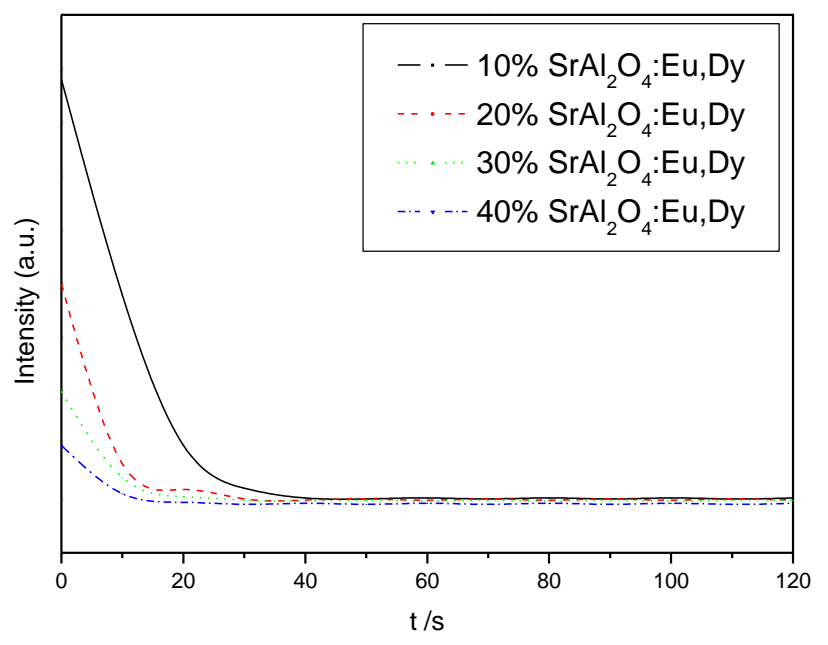

Figure. 1 Decay profiles of afterglow for the luminescent glass with various contents of $\mathrm{SrAl}_{2} \mathrm{O}_{4}: \mathrm{Eu}^{2+}$, $\mathrm{Dy}^{3+}$ phosphors

Fig.2 gives the decay profiles of afterglow for the LGs with $30 \mathrm{wt} \% \mathrm{SrAl}_{2} \mathrm{O}_{4}$ : $\mathrm{Eu}^{2+}, \mathrm{Dy}^{3+}$ phosphors at different firing temperature for $30 \mathrm{~min}$. The luminescent intensities decrease with increasing firing time duration and firing temperature. It is mainly because that the partial $\mathrm{Eu}^{2+}$ ions are oxidized forming $\mathrm{Eu}^{3+}$ ions, and it leads to luminescent intensities decreasing quickly. But the crystal phase is no change and is strontium aluminate crystal during the process of heating (Fig.3). 


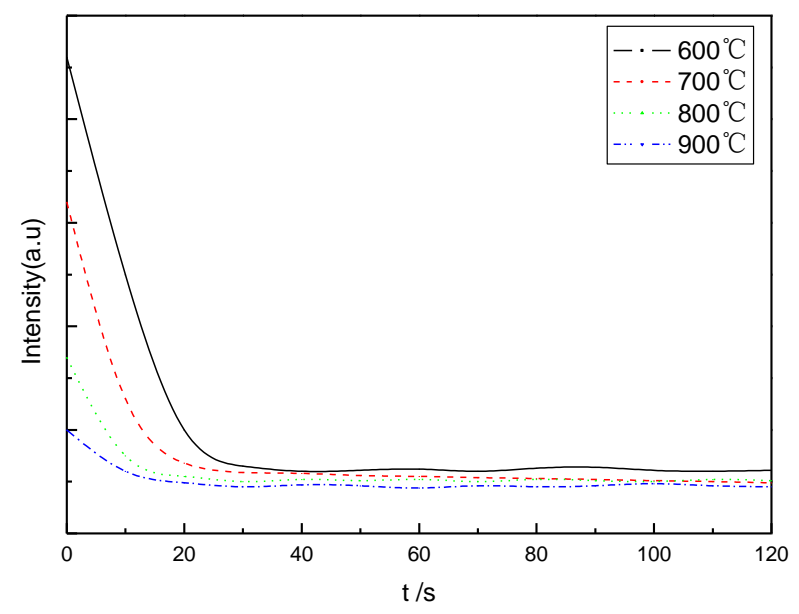

Figure. 2 Decay profiles of afterglow for the LGs with $30 \mathrm{wt} \% \mathrm{SrAl}_{2} \mathrm{O}_{4}: \mathrm{Eu}^{2+}$, $\mathrm{Dy}^{3+}$ phosphors at different firing temperature for $30 \mathrm{~min}$
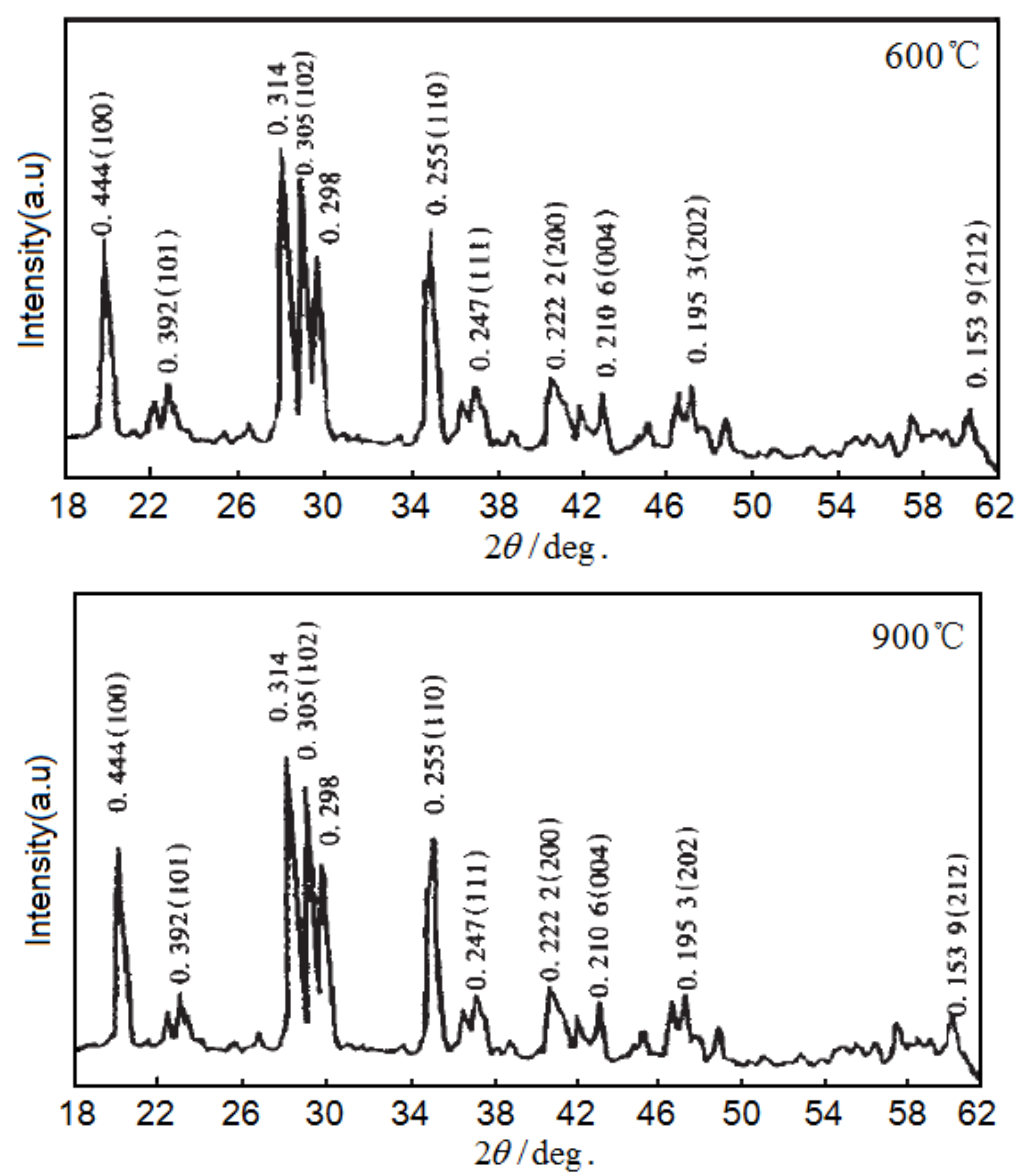

Figure. 3 XRD patterns of the LGs with $30 \mathrm{wt} \% \mathrm{SrAl}_{2} \mathrm{O}_{4}: \mathrm{Eu}^{2+}$, $\mathrm{Dy}^{3+}$ phosphors after heat treatment

Fig. 4 shows the excitation and the emission spectra respectively. The excitation and the emission spectra indicate the luminescence is originated from the $5 \mathrm{~d} 4 \mathrm{f} \rightarrow 4 \mathrm{f}$ transition of $\mathrm{Eu}^{2+}$ in the $\mathrm{SrAl}_{2} \mathrm{O}_{4}$ : $\mathrm{Eu}^{2+}, \mathrm{Dy}^{3+}$ phosphors. The results indicate that the luminescence of the glasses is originated from the $\mathrm{SrAl}_{2} \mathrm{O}_{4}: \mathrm{Eu}^{2+}, \mathrm{Dy}^{3+}$ phosphors in the samples. The mechanism of the long lasting phosphorescence in 
$\mathrm{SrAl}_{2} \mathrm{O}_{4}: \mathrm{Eu}^{2+}, \mathrm{Dy}^{3+}$ phosphors has been investigated ${ }^{11]}$. In this study, we suggest that the mechanism of the luminescent glasses are the same as that of $\mathrm{SrAl}_{2} \mathrm{O}_{4}: \mathrm{Eu}^{2+}, \mathrm{Dy}^{3+}$. After irradiation by the fluorescent lamp, electrons and holes were formed in the luminescent glasses . A parts of electrons or holes are trapped by trapping centers. Since the trap depth is broadly distributed and shallow, the electrons or holes can be thermally released at room temperature and long lasting afterglow luminescence is brought about.

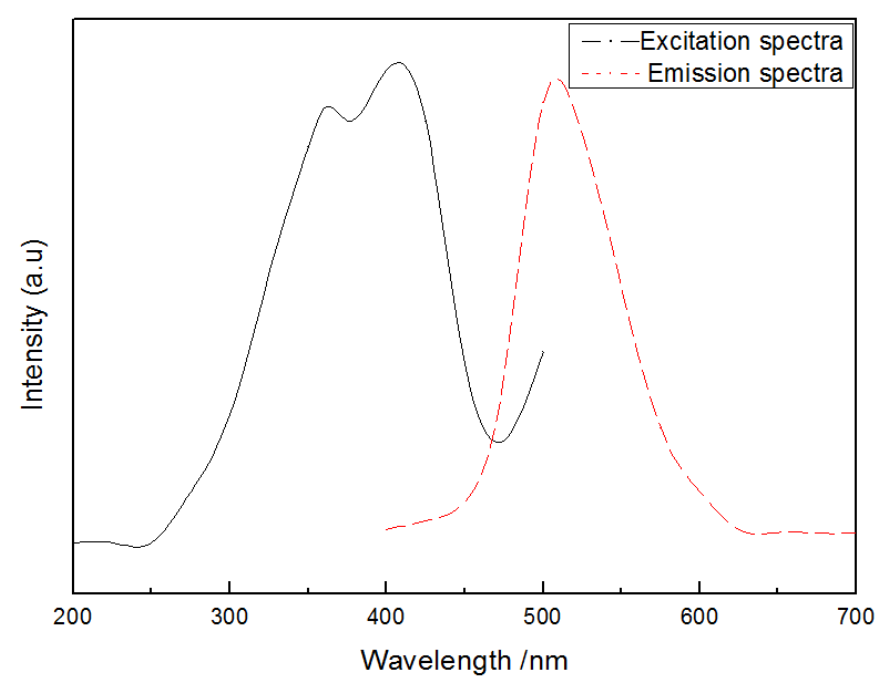

Figure. 4 Excitation spectra and Emission spectra of the LG with $30 \mathrm{wt} \% \mathrm{SrAl}_{2} \mathrm{O}_{4}: \mathrm{Eu}^{2+}, \mathrm{Dy}^{3+}$ phosphors at $700^{\circ} \mathrm{C}$ for $20 \mathrm{~min}$. The exciting wavelength is from 300 to $480 \mathrm{~nm}$ and the emitting wavelength is $510 \mathrm{~nm}$.

\section{Summary}

Bright long afterglow LGs are prepared by firing the mixed $\mathrm{SrAl}_{2} \mathrm{O}_{4}: \mathrm{Eu}^{2+}, \mathrm{Dy}^{3+}$ phosphors and matrix glasses together under an ambient atmosphere. It is found that the LGs show bright and long afterglow luminescence. What's more, the LGs can exhibit higher brightness and longer afterglow after firing at lower temperature and shorter time. The optimum content of the $\mathrm{SrAl}_{2} \mathrm{O}_{4}: \mathrm{Eu}^{2+}, \mathrm{Dy}^{3+}$ phosphors in the LGs are $30 \mathrm{wt} \%$.

\section{References}

[1] F. C. Pallila, A. K. Levine, M. R.Tomkus, Fluorescent properties of alkaline earth aluminates of the type $\mathrm{Mal}_{2} \mathrm{O}_{4}$ activated by divalent europium. J . Electrochem. Soc., 115(1968 )642-644

[2]V. Abbruscato, Optical and electrical properties of $\mathrm{SrAl}_{2} \mathrm{O}_{4}: \mathrm{Eu}^{2+}$. J.Electrochem. Soc . ,118(1971)930-934

[3] X.Y.Zhang, X.Y.Mi, Xiao Zhiyi, et al. Study on rare earth doped long luminescence glass. Spectroscopy Spect.Anal. , 25 (2005) 1756-1759

[4] L iuMing, Ma J ian, Zhang Baogang, Preparation and p roperties of rare-earth doped luminescent glass. J. M ater.Engin. , 2007, 5: 48252

[5] Z. L Tang, Zhang F, Zhang Z T, et al. Luminescent p roperties of $\mathrm{SrAl}_{2} \mathrm{O}_{4}$ :Eu , Dymaterial $\mathrm{p}$ repared by gelmethod, J. Europ. Ceram. Soc., 20 (2000) 2129-2132. 
[6] A. Bessière, S. K. Sharma, N. Basavaraju, K. R. Priolkar, L. Binet, B. Viana, A. J. J. Bos, T. Maldiney, C. Richard, D. Scherman, D. Gourier, Storage of Visible Light for Long-Lasting Phosphorescence in Chromium-Doped Zinc Gallate, Chem. Mater., 26(2014)1365-73

[7] S. Tanabe, S. Fujita, A. Sakamoto, S. Yamamoto, Glass Ceramics for Solid-State Lighting, Ceram. Trans., 173 (2006)19-25

[8] N. Tarasaki, H. Zhang, H. Yamada, N.C. Xu, "Mechanoluminescent Light Source for a Fluorescent Probe Molecule," Chem. Comm., 47 (2011)8034-8036

[9]F. Clabau, X. Rocquefelte, T.L. Mercier, P. Deniard, S. Jobic, and M.H. Whangbo, Formulation of Phosphorescence Mechanisms in Inorganic Solids Based on a New Model of Defect Conglomeration, Chem Matt, 18(2006)3212-3220

[10] J. Chen, F. Cu, C. Li, Influence of Precalcination and Boron-Doping on the Initial Photoluminescent Properties of SrAl2O4:Eu,Dy Phosphors,Cryst. Growth Des., 8(2008) 3175-3179

[11]A. Nag, T. N. R. Kutty, Role of B2O3 on the Phase Stability and Long Phosphorescence of $\mathrm{SrAl}_{2} \mathrm{O}_{4}: \mathrm{Eu}, \mathrm{Dy}, ” J$. Alloy. Comp, 354, 221-31 (2003) 